\title{
NOTA SÔBRE SCYLLARIDES BRASILIENSIS RATHBUN E SUA OCORRÊNCIA NO LITORAL DO ESTADO DE SÃO PAULO
}

\author{
F. de P. Andrade Ramos
}

O gênero Scyllarides foi criado por Gill (1898, p. 98-99) para receber alguns representantes da família Scyllaridae, até então incluidos no gênero Scyllarus Dana, 1852.

Como é sabido, até o presente, foram assinaladas na costa brasileira as seguintes espécies: Scyllarides aequinoctialis (Lund), da Bahia (Smith 1869, em Verrill 1922-924, p. 19) ; Rio de Janeiro (Moreira 1905, p. 127; De Man 1916, p. 65) ; Santos e Ilha de S. Sebastião (Luederwaldt 1919, p. $431 ; 1929$, p. 52). Em Santos e São Sebastião, Luederwaldt (1929, p. 52) assinalou também a presença de Scyllarus arctus L., dada como frequentadora do litoral do Rio de Janeiro, por Moreira (l. c.,) e por De Man (l. c., p. 64). Sôbre esta espécie, Schmitt (1935, p. 174) diz apenas: Brasil. Êste autor considera S. americanus como habitante da costa do Rio de Janeiro.

Rathbun (1906, p. 113) desereveu Scyllarides brasiliensis, baseado em um exemplar proveniente da Bahia, ocorrência que De Man (1. c.,) confirma. Dêsse modo, até o presente, parecem existir quatro espécies distintas ao longo do litoral brasileiro.

Examinando os espécimes da coleção do Departamento de Zoologia, da Secretaria da Agrieultura, do Estado de S. Paulo, verificamos nela figurar um exemplar rotulado com o nome de Scyllarus aequinoctialis Lund (n. ${ }^{\circ}$ 574), eapturado em 1907 na Ilha de S. Sebastião e retirado do estomago de uma garoupa. O crustáceo possue o telson danificado, nêle não se notando mais vestigios de manchas no primeiro somito abdominal. As medidas são as seguintes: comprimento total, sem o telson, $84 \mathrm{~mm}$.; comprimento da carapaça $47 \mathrm{~mm}$.; maior largura da carapaça $44 \mathrm{~mm}$.; largura anterior da carapaça $42 \mathrm{~mm}$; ; largura posterior da earapaça $38 \mathrm{~mm}$; distância entre as órbitas $24 \mathrm{~mm}$.

O exemplar de Scyllarus arctus L., (n. $\left.{ }^{0} 749\right)$, da coleção daquele Departamento, foi capturado em 1897, figurando, como local de origem, apenas a palavra: Brasil. Como a espécie anteriormente referida, esta 
foi retirada do estomago de uma garoupa. Está bem conservada, mede $45 \mathrm{~mm}$. de comprimento total, tendo a carapaça $16 \mathrm{~mm}$. na sua maior largura. Os seus caractéres são bem típicos e as esculturações dos somitos idênticas às constantes da fotografia da estampa VII, do trabalho de Verrill (1. c.,).

No presente trabalho estudaremos Scyllarides brasiliensis Rathbun, assinalando a sua ocorrência no litoral do Estado de São Paulo. Infelizmente, ao descrever a espécie, a autora dela nos deu descrição muito sumária, contida em pouco mais de 20 linhas e desacompanhada de fotografia ou desenho elucidativo. A diagnóse, no entretanto, mau grado o seu laconismo, é suficientemente clara para o reconhecimento da espécie.

Os caractéres dos indivíduos que temos em mãos correspondem perfeitamente aos de Scyllarides brasiliensis, como se verá pela diagnóse dada a seguir. Julgamos conveniente fazer referência a êsse exemplar, primeiramente em virtude de se tratar de espécie um tanto rara, que não figura literatura especializada sôbre os Macrura, a partir de 1906, salvo rapidíssima referência feita por De Man, em 1916. Em segundo lugar, parecenos se resta a primeira vez em que se dilata um pouco mais para o sul a área de expansão geográfica da espécie, até então só referida como ocorrente na costa do Estado da Bahia.

Agradecemos ao snr. Dr. Oliverio Mario de O. Pinto, DD. Diretor do Departamento de Zoologia, da Secretaria da Agricultura, por nos ter gentilmente facultado o acesso à bibliografia e o exame do material que figura nas coleções do Departamento que dirige. Aos Snrs. Profs. Drs. Ernesto Mareus e Paulo Sawaya, agradecemos também o valioso auxílio que nos foi prestado pela biblioteca da Universidade de S. Paulo.

Ao snr. J. de Paiva Carvalho, Chefe da Secção da Fauna Marítima, do Instituto Paulista de Oceanografia, agradecemos a orientação imprimida ao presente trabalho; à Exma. Sta. Joanna de Paula Arruda, os retoques efetuados nas fotografias que ilustram a presente nota e ao snr. Kossako Kikuchi, a remessa do material que é objeto do presente estudo.

Scyllarides brasiliensis Rathbun.

Est. I-II

Fotos I e II

Scyllarides brasiliensis Rathbun 1906, vol. XIX, p. 113.

Denominação vulgar: Lagosta. Vasconcellos (1938, p. 67) regista os nomes de Lagosta sapata e Lagostim, atribuidos a Scyllarus arctus e Lagosta sapateira, Cigarra e Fradinho, aplicáveis a Scyllarides aequinoctialis. 
Denominação estrangeira: Cigale de mer (França). Sea Cry-fish, Spanish Lobster (América do Norte). Bärenkrebse (Alemanha).

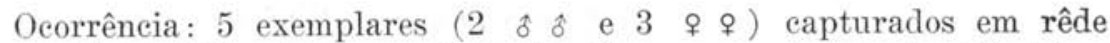
"trawl" pelo barco Dois Irmãos, provenientes de Ubatuba; 8 exemplares (4 $\hat{\delta}$ ô e 4 우 ㅇ) pescados em idênticas condiȩões nas cercanias da Ilha Vitória, situada ao norte da Ilha de São Sebastião, no litoral norte do Estado de São Paulo.

Diagnósoe: Espécie eujo porte variou, nos ô ô, de 121 a $168 \mathrm{~mm}$.,

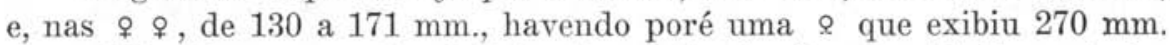
As medidas foram tomadas da báse das antênulas à extremidade posterior do telson. Cefalotorax espesso e duro, granuloso, com largura, na porção

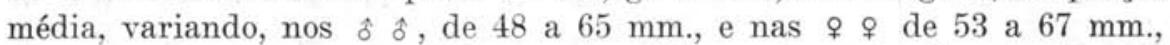
salvo em uma que possue $93 \mathrm{~mm}$.; os flancos laterais são providos de denticulações mais ou menos acentuadas. As órbitas encontram-se nos cantos anteriores externos e são encaixadas nas abas da carapaça. As antênulas são mais ou menos longas e largas, formadas por segmentos achatados, em forma de pá e semelhantes a escamas; margens externas das três primeiras articulações das antênas, denteadas, com dentes achatados, sendo o anti-penúltimo segmento desprovido de dentes proeminentes nos ângulos. Antêna medindo de 32 a $44 \mathrm{~mm}$., salvo no maior exemplar que atingiu a $52 \mathrm{~mm}$. Rostro proeminente. Dorso fortemente granuloso, existindo pigmentações vermelho-arroxeadas mais concentradas nas regiões eardíaca e branquial; região gástrica às vêzes com manchas escuras evidentes, de contorno mal definido e unidas na linha mediana da carapaça; região frontal com duas aglomerações de manchas vermelho-arroxeadas sôbre a linha mediana da carapaça.

Primeiro segmento abdominal apresentando duas grandes manchas redondas, de vivo vermelho-arroxeado, bem afastadas uma da outra, achando-se o segmento desprovido de quilha mediana. Segundo, tereeiro, quarto e quinto segmentos eom ligeira quilha no meio. Lóbulos laterais um tanto alongados na região ventral, providos de margens denteadas. Pernas fortes, mais ou menos compridas e achatadas, com carena acentuada na face dorsal e proeminências terminais nos artículos, excrescências essas que se tornam gradativamente menos pronunciadas do primeiro ao quinto par.

O telson é mais largo do que comprido. O colorido geral é vermelhoarroxeado, com tonalidades alaranjadas marginando as antênulas e antênas.

As medidas obtidas nos 13 exemplares por nós examinados são as seguintes : 


\begin{tabular}{|c|c|c|c|c|c|c|c|c|c|c|c|c|c|}
\hline & \multicolumn{13}{|c|}{$\begin{array}{l}\text { MEDIDAS EM MILIMETROS } \\
\text { Ex e m } 1 \text { a } r \text { es Núm e } \mathrm{r} \text { o }\end{array}$} \\
\hline & 1 & 2 & 3 & 4 & 5 & 6 & 7 & 8 & 9 & 10 & 11 & 12 & 13 \\
\hline $\mathrm{S} \mathrm{EX} \mathrm{O}$ & q & q & $q$ & $\delta$ & $\delta$ & q & $\delta$ & $\delta$ & $q$ & $q$ & $\delta$ & $q$ & $\delta$ \\
\hline Comprimento total (1). & 138 & 140 & 140 & 131 & 121 & 270 & 168 & 152 & 171 & 168 & 147 & 130 & 157 \\
\hline $\begin{array}{l}\text { Compr. da base do ros- } \\
\text { tro ao telson .... }\end{array}$ & 136 & 132 & 132 & 126 & 119 & 250 & 161 & 148 & 166 & 162 & 143 & 125 & 152 \\
\hline Compr. da carapaça ... & 61 & 57 & 61 & 58 & 54 & 104 & 72 & 65 & 72 & 72 & 65 & 56 & 67 \\
\hline $\begin{array}{l}\text { Compr. do abdomen } \\
\text { (sem o telson) } \ldots\end{array}$ & 65 & 64 & 63 & 55 & 52 & 115 & 73 & 70 & 80 & 76 & 65 & 59 & 65 \\
\hline Compr. do telson .... & 22 & 21 & 23 & 20 & 20 & 45 & 25 & 25 & 29 & 24 & 24 & 22 & 27 \\
\hline $\begin{array}{l}\text { Larg. carapaça (porção } \\
\text { anter.) } \ldots \ldots \ldots \ldots \\
\end{array}$ & 52 & 51 & 51 & 50 & 48 & 82 & 64 & 56 & 63 & 64 & 57 & 50 & 58 \\
\hline $\begin{array}{c}\text { Larg. earpaça (porção } \\
\text { média) } \ldots \ldots \ldots \ldots \\
\end{array}$ & 55 & 53 & 54 & 51 & 48 & 93 & 65 & 59 & 65 & 67 & 58 & 51 & 60 \\
\hline $\begin{array}{l}\text { Larg. carapaça (porção } \\
\text { inferior).......... }\end{array}$ & 48 & 49 & 48 & 47 & 45 & 88 & 59 & 53 & 61 & 63 & 53 & 47 & 55 \\
\hline Larg. entre 6rbitas ... & 36 & 35 & 36 & 35 & 34 & 60 & 45 & 40 & 44 & 45 & 39 & 35 & 41 \\
\hline Larg. do telson . ...... & 25 & 23 & .24 & 23 & 23 & 47 & 30 & 27 & 31 & 31 & 26 & 24 & 28 \\
\hline $\begin{array}{r}\text { Distancia entre as orbi- } \\
\text { tas e os bordos lat. } \\
\text { da carapaga ...... }\end{array}$ & 11 & 10 & 10 & 10 & 9 & 15 & 12 & 11 & 13 & 13 & 12 & 10 & 12 \\
\hline Larg. do $10^{\circ}$ somito .. & 11 & 11 & 12 & 12 & 11 & 20 & 15 & 14 & 15 & 16 & 13 & 11 & 14 \\
\hline Larg. do $20^{\circ}$ somito .. & 14 & 16 & 18 & 16 & 12 & 25 & 21 & 19 & 22 & 23 & 18 & 16 & 21 \\
\hline Larg. do $3 .^{\circ}$ somito .. & 14 & 16 & 17 & 14 & 15 & 29 & 22 & 20 & 23 & 23 & 19 & 17 & 21 \\
\hline Larg. do $4 .^{\circ}$ somito .. & 15 & 15 & 17 & 14 & 14 & 25 & 16 & 18 & 21 & 21 & 17 & 14 & 15 \\
\hline Larg. do $50^{\circ}$ somito .. & 12 & 12 & 18 & 12 & 11 & 20 & 12 & 14 & 17 & 16 & 12 & 10 & 11 \\
\hline Larg. do $6 .^{\circ}$ somito .. & 10 & 12 & 11 & 11 & 10 & 22 & 14 & 13 & 15 & 13 & 12 & 11 & 12 \\
\hline Compr. da antena ... & 34 & 35 & 35 & 31 & 32 & 52 & 44 & 39 & 42 & 43 & 37 & 34 & 39 \\
\hline
\end{tabular}

Concordamos plenamente com Verrill (l. e.,) quando diz: "S. braziliensis pode ser prontamente identificada, quando de fixação recente, pelas suas eôres vermelho-arroxeadas muito vivas, com os bordos das articulações, das antenas, etc., purpureos vivas ou "magenta" e, especialmente, pela ausência de união ou aproximação entre as grandes manchas redondas e vermelha, situadas na face dorsal do primeiro segmento abdominal. Em S. braziliensis, êsse segmento possue um par de manchas, de colorido vermelho vivo ou "magenta", ambas grandes, evidentes, bem

(1) Da base das antênulas à extremidade posterior do telson. 
afastadas ou situadas perto da linha mediana, entre o centro e a margem, encontrando-se, também, em muitos exemplares, máculas mal definidas, vermelho escuras ou pardo vivas, além do par mediano".

Em todos os nossos exemplares, constatamos exatamente o que foi referido por Rathbun (l. c., p. 113), isto é, ser o primeiro segmento abdominal "provido de duas manchas vermelhas, eireulares e distantes uma da outra, apresentando-se o interespaço existente entre ambas, maior do que a distância que separa eada mancha do flanco externo marginal do segmento".

Confrontando-se as medidas dos nossos exemplares eom as Verrill e Rathbun, obtem-se o resultado constante do quadro abaixo:

\begin{tabular}{|c|c|c|c|c|}
\hline \multirow{3}{*}{ S E X O } & \multicolumn{4}{|c|}{ MEDIDAS EM MILIMETROS } \\
\hline & \multirow{2}{*}{$\frac{\text { Verrill }}{\delta}$} & \multirow{2}{*}{$\frac{\text { Rathbun }}{q}$} & \multicolumn{2}{|c|}{$\mathrm{R} \mathrm{a} \mathrm{mos}$} \\
\hline & & & $\delta$ & 우 \\
\hline Compr. total .............. & 295 & - & 121 a 168 & 130 a 270 \\
\hline Compr. da antêna $\ldots \ldots \ldots \ldots$ & 62 & - & 31 a 44 & 34 a 52 \\
\hline Compr. da carapaça ......... & 90 & 86,5 & 54 a 72 & 56 a 104 \\
\hline Compr. abdomen ao telson ... & 100 & - & 75 a 103 & 83 a 162 \\
\hline Compr. do telson $7 . . . \ldots \ldots \ldots$ & 28 & - & 23 a 30 & 23 a 47 \\
\hline Larg. carapaça (anterior) ..... & 82 & - & 48 a 64 & 50 a 82 \\
\hline Larg. carapaça (centro) ...... & 84 & 80,5 & 48 a 65 & 51 a 93 \\
\hline Larg. carapaça (posterior) .... & - & - & 45 a 59 & 47 a 88 \\
\hline Larg. entre as órbitas ........ & 56 & 一 & 35 a 41 & 35 a 60 \\
\hline $\begin{array}{c}\text { Distancia entre as órbitas e os } \\
\text { bordos da carapaça } . . . . .\end{array}$ & 11,5 & 一 & 9 a 12 & 10 a 15 \\
\hline Larg. do $10^{\circ}$ seg. abdominal .. & - & 一 & 11 a 15 & 10 a 20 \\
\hline Larg. do $60^{\circ}$ seg. abdominal .. & 17 & - & 10 a 12 & 10 a 22 \\
\hline Larg. do telson (1) .......... & 46 & - & 23 a 30 & 23 a 47 \\
\hline
\end{tabular}

Discussão: Os machos eapturados no litoral paulista apresentam porte bem inferior ao do material examinado por Verrill; mesmo a maior $\uparrow$ por nós captura $(270 \mathrm{~mm})$, não atinge tamanho semelhante ao en-

(1) $\mathrm{Na}$ coluna em que figuram os exemplares examinados pelo autor (Ramos) as medidas foram tomadas na báse do telson. 
contrado por aquêle autor. Em relação ao comprimento das antênas, as dos nossos exemplares são bem menores. Quanto ao comprimento do cefalotorax, os nossos machos possuem-nos de menores proporęões, mas o constatado em uma das nossas fêmeas é bem maior do que o encontrado por Rathbun. O comprimento do abdomen até o telson é mais ou menos idêntico, em comparação com o do macho de Verrill, posto que em uma das fêmeas da nossa coleção êle se apresente bem maior. A largura do telson, na porȩão anterior, condiz com o que foi encontrado por Verrill, sendo, porém, em uma das nossas fêmeas, muito maior. A largura do cefalotorax, na porção média, é menor nos nossos machos e igual, quando comparada a da fêmea de maior porte que possuimos. As distâncias entre as órbitas é quase a mesma, exceção feita quanto à maior fêmea da nossa coleção. A largura do $6 .^{\circ}$ somito abdominal (no centro) é menor nos nossos machos e bem mais acentuada na nossa maior fêmea. A largura do telson é inferior em todos os nossos exemplares, apresentando-se mais amplo em uma das nossas fêmeas.

Do confronto, conclue-se que Verrill deve ter tido em mãos um macho bem desenvolvido, mais ou menos do porte da fêmea que faz parte do material por nós estudado. Pena é que Rathbun se tenha manifestado, apenas, sôbre o comprimento e a largura (no meio) da carapaça da fêmea por ela examinada.

Pelo exame das diagnóses constantes da literatura especializada que tivemos ao nosso alcance, verifica-se que a rugosidade da carapaça de $S$. brasiliensis é maior do que a existente em S. aequinoctialis e menor do que a de $S$. americanus. O caráter representado pelas máculas redondas, vermelho-arroxeadas, é útil ao trabalho taxonômico. Em S. aequinoctialis, elas se acham unidas anteriormente e situadas no centro do primeiro somito abdominal; em S. brasiliensis, elas são bem afastadas e dispostas no ponto central existente entre o meio e o bordo lateral do somito; em $S$. americanus, existem pràticamente 3 máculas, uma no centro e duas laterais, estas menos evidentes do que aquelas. Quanto ao tamanho, as medidas evidenciam ser muito variáveis, tanto os comprimentos como as maiores larguras. No entretanto, a maior espécie até hoje verificada parece ter sido $S$. americanus da qual se conhece um exemplar com $350 \mathrm{~mm}$.

Habitos: No nosso meio, pouco se sabe a respeito dos habitos peculiares aos representantes da família Scyllaridae. Boone (1927, p. 88), referindose a $S$. aequinoctialis, diz que, nas Indias Ocidentais, a espécie ocorre, em abundância, em águas profundas dos recifes externos, frequentando desde as águas salôbras até profundidades de cêrea de 100 metros, acrescentando que "as suas antenas largas e achatadas bem como os dactilos fortes permitem-no abrir sulcos à superfície da areia ou da lama, revirando pequenas pedras, à eata de moluseos, vermes e outros quitutes semelhantes, O vigor demonstrado por êsse exemplar, capaz de erguer pedras maiores do que o seu próprio peso, constitue espetáculo supreendente. Introduzindo as antênas em forma de pá no bordo de uma pedra, segura firmemente com o dáctilo em forma de unha um apoio circunvizinho; o abdomen, secundado pela corcova do dorso, erguem o calhau 
e, em supremo esforço, empurram-no para a frente. $O$ dáctilo robusto sulca o terreno anteriormente ocupado pela pedra, capturando numerosos e diminutos organismos que sob ela se ocultavam".

Como acontece com os demais membros da família, S. brasitiensis é dotado de visão muito escassa, sendo, em linhas gerais, um animal vagaroso.

Valôr econômico: No nosso meio, não nos consta que os representantes da família Scyllaridae tenham qualquer valôr econômico apreciável. Sabemos, apenas, que alguns pescadores, sobretudo os de origem japonesa, os consideram excelentes como alimento, ingerindo-os sempre que os encontram.

Besnard (1948, p. 120), que estudou com especial interêsse os crustáceos europeus sob o ponto de vista econômico, referindo-se aos componentes do gênero Scyllarus e, especialmente a $S$. latus, diz: "Esta espécie muito carnuda, possuidora de carne de excelente qualidade, infelizmente é muito rara e, consequentemente, não apresenta qualquer interêsse industrial",

\section{RESUMO}

Trata o presente trabalho da ocorrência de Scyllarides brasiliensis Rathbun, no litoral do Estado de São Paulo. O autor examinou 5 exemplares ( 2 o $\hat{\delta}$ e 3 우) provenientes de Ubatuba e 8 exemplares ( $4 \hat{\delta}$ os e 4 우 \&) oriundos da Itha Vitória, situada no litoral norte do Estado de São Paulo, nas proximidades da Ilha de São Sebastião.

A maioria dos especialistas que se ocupam do grupo parece não ter tomado em consideração o trabalho de Gill (1898), que subidividiu o gênero Scyllarus em dois: Scyllarus e Scyllarides, colocando, quase sempre, no primeiro gênero, espécies que devem figurar no segundo. Quase a totalidade dos indivíduos da família Scyllaridae que frequenta a costa brasileira, faz parte do gênero Scyllarides.

Estabelecendo confronto entre as medidas dos exemplares do litoral bandeirante e os obtidos por Verrill e Rathbun, o autor passa em rápida revista os seus hábitos; referindo-se ao valôr econômico por êles representado.

\section{ABSTRACT}

This paper mentions the presence of Scyllarides brasiliensis Rathbun, in the littoral zone of the State of S. Paulo. The author examined 5

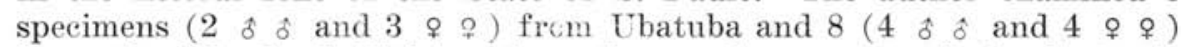
from the Island of Vitória, along the northern coast of the State, in the surroudings of the island of S. Sebastião.

Many of the specialists that studied the group overlooked the work of Gill (1898) that splitted the genus Scyllarus in Scyllarus and Scyllarides and thus several species that ougth to be placed in the latter mentioned genus are still described as belonging to Scyllarus. Most of the species that inhabit the brazilian coast must be referred to Scyllarides. 
The author compares the measurements of the present specimens with those studied by Verrill and Rathbun, and rapidly refers the species' habits and its economic value.

\section{BIBLIOGRAFIA}

BESNARD, W., 1948 - Les produits d'origine marine et fluviale, p. 1-366. Payot, Paris.

BOONE, L., 1927 - Crustacea from tropical East American Seas. Bul. Bingham Oceanogr. Coll., vol. I, art. 2, p. 1-147. N. Y.

DE MAN, J. G., 1916 - The Deeapoda of the Siboga Expedition, Part. III. Families Eryonidae, Palinuridae, Scyllaridae and Nephropsidae. Siboga Exp., p. 1-318. Leiden.

GILL, T., 1898 - The Crustacean genus Seyllarides, Seienee, N. S., vol. VII, n. ${ }^{\circ}$ 160, p. 98-99. N. Y.

LUEDERWALDT, H., 1919 - Lista dos Crustaceos superiores (Thoracostraca) do Mus. Paulista, que foram encontrados 110 Estado de São Paulo por H. Luederwaldt, naturalista do Museu Paulista. Rev. Mus. Paulista, vol. XI, p. 429-438. São Paulo.

LUEDERWALDT, H., 1929 - Resultados de uma excursão scientifica à ilha de São Sebastião, no litoral do Estado de São Paulo e em 1925. Rev. Mus. Paulista, vol. XVI, p. 1-79. São Paulo.

MOREIRA, C., 1905 - Campanhas de pesea do Annie. Crustáceos. Arch. Mus. Nac. Rio de Janeiro, vol. XII, p. 1-190, est. I-III. Rio de Janeiro.

RATHBUN, M. J., 1906 - A new Scyllarides from Brazil. Proc. Biol. Soc. of Washington, vol. XIX, p. 113-114. Washington.

SCHMITT, W. L., 1935 - Crustacea Macrura and Anomura of Porto Rico and the Virginia Islands. Sei. Survey of Porto Rico and the Virginia Islands. New York Acad. Sci., vol. XV, pl. 2, p. 125-262. N. Y.

VASCONCELLOS, A., 1938 - Vocabulario de Ietiologia e Pesea. Edigão da Liga Naval Brasileira, p. 1-147. Recife.

VERRILL, A. E., 1922-1924 - Decapod Crustacea of Bermuda. Part. II, Macrura. Trans. Conn. Acad. of Arts and Sciences, vol. XXVI, p. 1-179. New Haven, Comn.. 


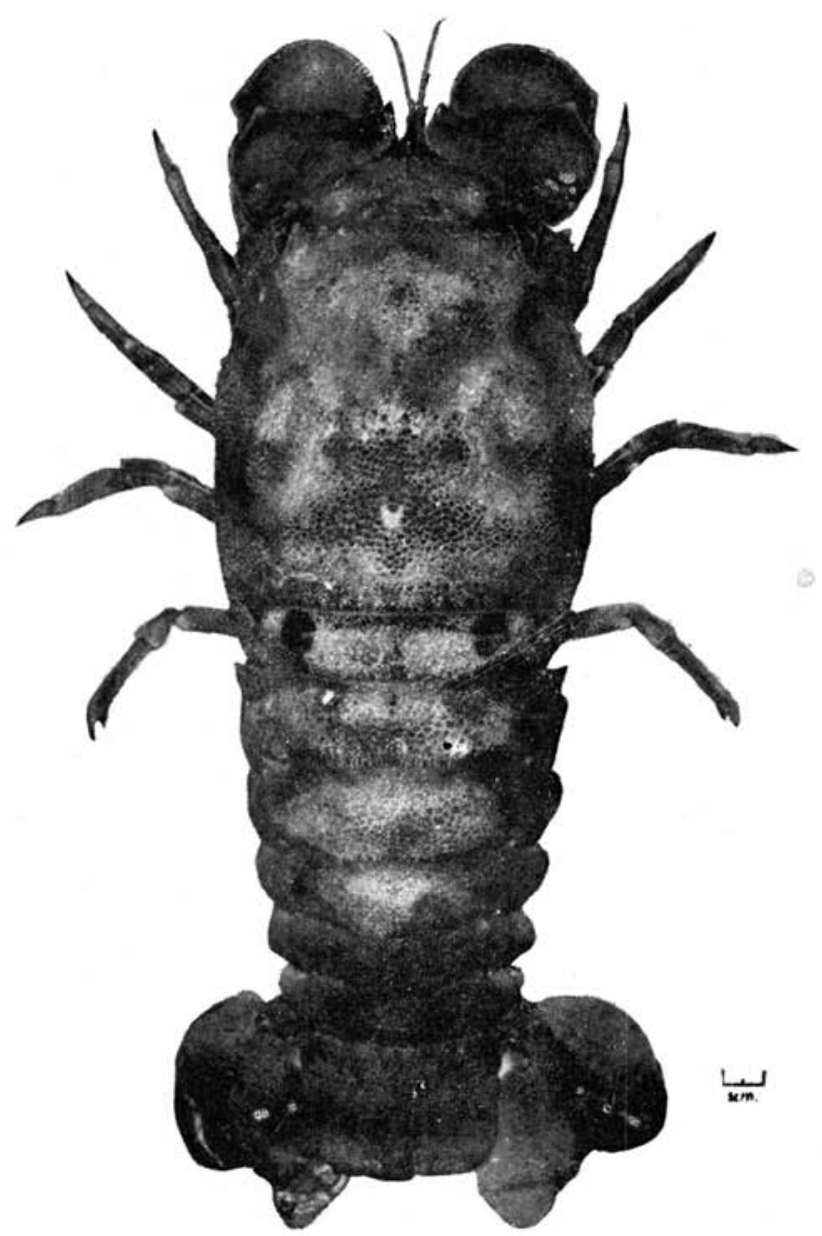

Foto I

Scyllarides brasiliensis Rathbun, $Q$ da Ilha Vitória.

Estado de S. Paulo (vista dorsal). 


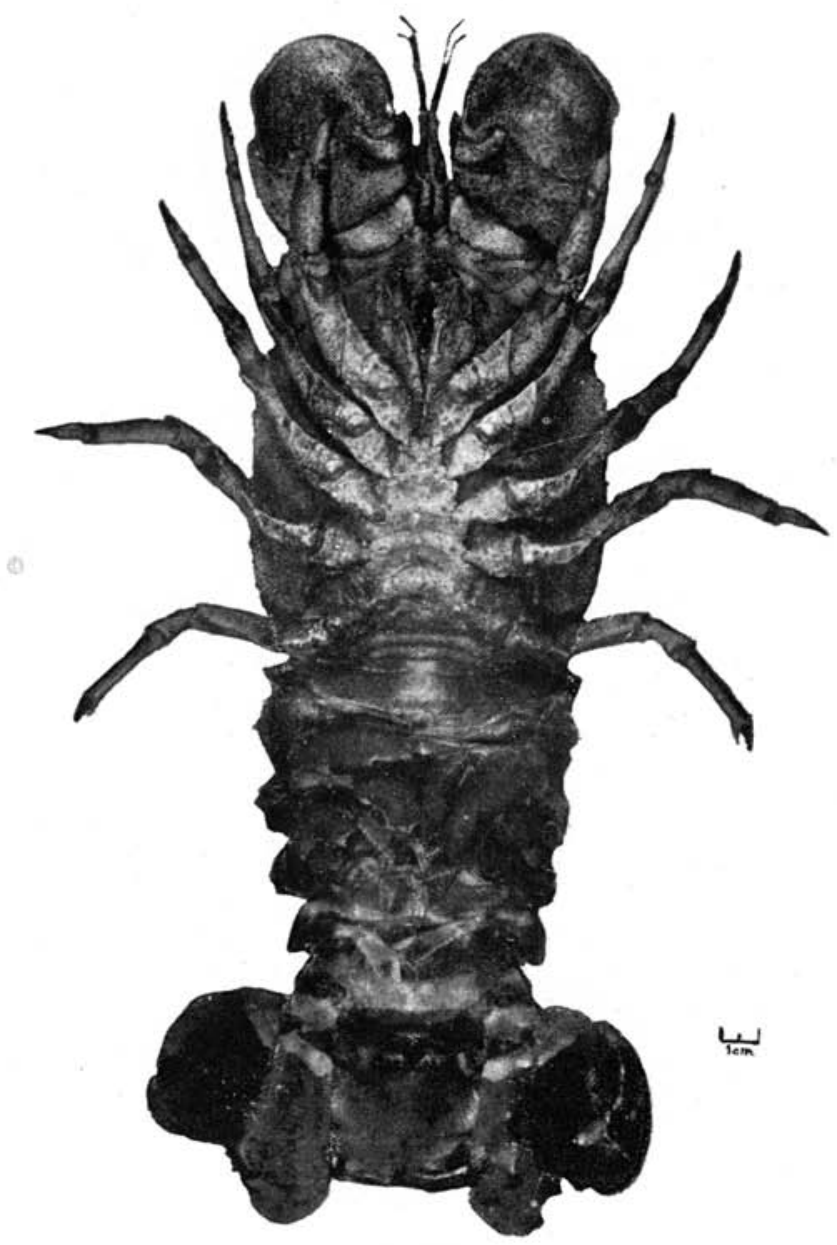

Foto II

Scyllarides brasiliensis Rathbun, $Q$ da Ilha Vitória, Estado de S. Paulo (vista dorsal). 